\title{
Editorial
}

\section{La bioética en el contexto de la pandemia por COVID-19}

\author{
DOI: $10.5377 /$ alerta.v3i2.10094
}

\author{
Nadia Patricia Rodríguez Villalta
}

Instituto Nacional de Salud, Departamento de Gobernanza y Gestión del Conocimiento, San Salvador, El Salvador.

Correspondencia

$\square$ nadia.rodriguez@salud.gob.sv

(D) 0000-0002-2725-921

\section{ACCESO ABIERTO}

Citación recomendada:

Rodríguez-Villalta NP. La

bioética en el contexto de

la pandemia por COVID-19.

Alerta. 2020;3(2):42-43.

DOl: 10.5377/alerta.v3i2.9549

\section{Recibido:}

14 de marzo de 2020.

\section{Aceptado:}

11 de mayo de 2020.

Publicado:

3 de julio de 2020.

Conflicto de intereses:

La autora declara no tener conflictos de interés con ninguna organización.
La pandemia ha llevado la investigación y las publicaciones a un ritmo de avance sin precedentes. A junio de 2020 se habían publicado más de 42700 artículos académicos sobre COVID-19'. Al ser esta una enfermedad polifacética y emergente, en la medida que se estudia, se descubren más afectaciones y surgen más preguntas que respuestas. Se necesita aún más tiempo e investigaciones para conocer todas las aristas clínicas y epidemiológicas de esta enfermedad, así como las repercusiones y secuelas a largo plazo. Por esto, se deben evitar las deducciones y conclusiones apresuradas.

Al mismo tiempo que existe la urgencia de investigar para generar evidencia sobre las mejores intervenciones, se deben tratar a los pacientes enfermos. Ante la inexistencia de un tratamiento eficaz, se ha permitido el uso compasivo de ciertos medicamentos que aún están siendo probados². Ambos procesos, investigación y manejo de pacientes, caminan de forma simultánea en esta pandemia.

Esto se convierte en un llamado a los profesionales de la salud, quienes diariamente toman decisiones clínicas. A recordar las enseñanzas de William Osler: el buen médico trata la enfermedad; el gran médico trata al paciente que tiene la enfermedad ${ }^{3}$. Para esto, se debe valorar el riesgo-beneficio en cada historia personal y prescribir únicamente las intervenciones que tienen suficiente evidencia de ser seguras y eficaces, sin causar daño.

La medicina basada en la evidencia ayuda a la toma de decisiones razonada, pero también se requiere el análisis crítico por parte de los lectores. Sin embargo, no siempre las intervenciones no probadas se desarrollan en el marco de protocolos de investigación. A la luz del dinamismo de esta pandemia, se convierte en un deber moral actualizar con frecuencia los protocolos de manejo y valorar desde la ciencia y la bioética aquellas decisiones difíciles.

Es aquí donde desempeña un rol importante la bioética, entendida como la ciencia que relaciona los valores y principios morales con la medicina, en sus diferentes dimensio$n^{4} s^{4}$ y se encarga de esclarecer dilemas éticos, a través de los comités de bioética. Estos deben ser multidisciplinarios, íntegros, totalmente capaces y confiables.

A lo largo de la historia de la ciencia, se han establecido acuerdos internacionales sobre las pautas bioéticas, que se ven reflejadas en diferentes declaraciones, como la de la Organización de las Naciones Unidas para la Educación la Ciencia y la Cultura (Unesco, por sus siglas en inglés). En condiciones ordinarias, las intervenciones se prueban en investigaciones ${ }^{2}$ y son los comités de ética quienes deben velar porque se respeten las pautas éticas de la declaración de Helsinki y se cumplan los objetivos de la investigación en seres humanos. Lo anterior con el fin de comprender las causas, evolución y efectos de las enfermedades, al evaluar continuamente estas intervenciones a través de la investigación, para que sean seguras, eficaces, efectivas, accesibles y de calidad ${ }^{5}$.

En esta pandemia, la Organización Mundial para la Salud (OMS) ha brindado recomendaciones para que las intervenciones no probadas, que no se encuentren dentro de una instancia de investigación, sean éti- 
camente aceptables. Esto implica que exista una justificación, como en este caso, donde no hay un tratamiento con eficacia comprobada y que no se dispongan de los recursos para iniciar ensayos clínicos de forma inmediata. Otro criterio es que sea factible la supervisión ética y regulatoria; es decir, sea aprobado por las autoridades del país, así como un comité de ética y que se genere un adecuado proceso de consentimiento informado, incluyendo su revocación en cualquier momento. Finalmente, debe existir una contribución a la generación de evidencia ${ }^{2}$. Sin embargo, sigue vigente el respeto a la dignidad, la confidencialidad, el valor y la autonomía de las personas como un derecho humano y como parte de sus libertades fundamentales 6 .

La revista Alerta se adhiere a las Declaraciones de Helsinki y a la Declaración Universal sobre Bioética y Derechos Humanos (2005) de la Unesco, consciente de que el respeto y bienestar de los seres humanos participantes tiene primacía sobre los intereses de la ciencia y de la sociedad?. Además, vela por la protección de los grupos vulnerables, sin doble estándar ${ }^{8}$, discriminación ni estigmatización ${ }^{6}$.

Esta pandemia se ha posicionado como una prioridad de investigación en el campo de la salud. Ha sido positiva la cooperación entre los investigadores a nivel internacional, las publicaciones han crecido exponencialmente y en esto ha contribuido el acceso abierto. Sin embargo, la ciencia enfrenta otros riesgos, pues la rapidez por publicar ha hecho que revistas de gran renombre hayan tenido que retractar artículos importantes ${ }^{9}$. También se ha abierto un espacio a la difusión de noticias sin respaldo científico comprobado con deficiencias metodológicas y recomendaciones inapropiadas o que atentan contra la seguridad y dignidad de las personas. Las revistas arbitradas, en este sentido, tienen una gran responsabilidad, como canal que comunica los avances de la ciencia. Se debe priorizar la calidad antes que la rapidez de publicación, por los errores que esto podría traer y su incidencia en la toma de decisiones.

Es así como Alerta busca, además de lo anterior, desarrollar una cultura de publicación que se sustente en la bioética desde el profesionalismo, la honestidad y la integridad que caracterizan a la ciencia.

\section{Referencias bibliográficas:}

1. Hook D, Porter S. How COVID-19 is Changing Research Culture. Junio 2020; DOI: 10.6084/m9.figshare.12383267

2. Organización Panamericana de la Salud. Uso de emergencia de intervenciones no probadas y fuera del ámbito de la investigación. Orientación ética para la pandemia de COVID-19, 25 de junio del 2020. Washington, DC: PAHO; 2020. Disponible en: https://iris.paho.org/ handle/10665.2/52430

3. Young Pablo, Finn Bárbara C, Bruetman Julio E, Emery John D. C, Buzzi Alfredo. William Osler: el hombre y sus descripciones. Rev. méd. Chile. 2012;140(9):1218-1227. DOI: 10.4067/S0034-98872012000900018

4. Vega Toro S, Novoa Sotta F. Aspectos éticos de la pandemia por COVID-19 en pediatría. Rev Chil Pediatr. Forthcoming 2020;91(4). DOI: $10.32641 /$ rchped.v91i4.2466

5. Asociación Médica Mundial. Declaración de Helsinki de la AMM-principios éticos para las investigaciones médicas en seres humanos. DOI: 10.17126/joralres.2013.009

6. Gros Espiell H. La Declaración Universal sobre Bioética y Derechos Humanos de la Unesco y la Declaración de Santo Domingo sobre Bioética y Derechos Humanos. Revista Brasileria de Bioetica. 2007;3(1):7-13. DOI: $10.26512 / \mathrm{rbb} . v 3 i 1.8162$

7. Cruz-Coke MR. universal de bioética y derechos humanos de UNESCO. Rev. méd. Chile. 2005 Sep;133(9):1120-1122. DOI: 10.4067/S0034-98872005000900019

8. Mazzanti Di Ruggiero, MA. Declaración de Helsinki, principios y valores bioéticos en juego en la investigación médica con seres humanos. Revista Colombiana de Bioética. 2011;6(1):125-144. Disponible en: https://www.redalyc.org/articulo. oa?id=189219032009

9. Rabin RC. The Pandemic Claims New Victims: Prestigious Medical Journals. The New york times. June 16, 2020. Fecha de consulta: 29 julio 2020. Disponible en: https://www.nytimes.com/2020/06/14/ health/virus-journals.html 